\title{
Methodological problems of natural and natural- technical systems based on the example of Primorsky Region
}

\author{
Lubov Lipina ${ }^{1 *}$, Vitalii Usikov ${ }^{1}$ and Nikolai Grehnev ${ }^{1}$ \\ ${ }^{1}$ Mining Institute of Far eastern branch of Russian Academy of Sciences, Khabarovsk, Russia
}

\begin{abstract}
Annotation. The paper shows that in the development of indigenous ore deposits, four main types of solid waste are formed, which affect natural systems and form the main processes of mining technogenesis. In general, the technogenic impact of mining processes on ecosystem components is diverse, so it becomes necessary to separate the stages of production. The technological and geological factors for the development of specific mine objects are of significant importance for the ecological state of naturaltechnical systems (NTS), the results of which should be taken into account in the ecological mapping of the NTS, taking into account the strongest component - the lithogenic base, which determines the geochemical background (the medium in which the chemical reactions take place).
\end{abstract}

\section{Introduction}

Natural-technical or natural-technogenic systems (NTS) significantly changed the natural environment. At present, on the Earth, equivalent systems are considered to be natural systems (receiving control from nature), technogenic (receiving control signals from society), both of which form natural-technogenic systems. The growing technological pressure on natural ecosystems leads to their quick and often irreversible destruction, which gradually assumes a global character. At the same time, the paradox of the situation is that the progressive degradation of nature takes place against the backdrop of the rapidly growing expenditures of mankind for its protection; and the energy resources necessary to preserve nature at the present level can be obtained only by technogenic destruction of this nature foundation - the Earth's lithosphere.

In his writings Academician VI Vernadsky noted that mankind has become a powerful geological and, possibly, a cosmic force capable of transforming nature on a large scale [1]. The life activity of mankind is not an external, accidental phenomenon on the earth's surface, it is closely connected with the structure of the earth's crust, enters into its mechanism and in this mechanism performs important functions without which man could not exist. [2] Interpreting Vernadsky's words we can say that no matter what extent the bowels of the earth are exhausted, society cannot exist when their use is no longer possible. Therefore, it is not possible to preserve the natural environment in its natural state during the development of subsurface resources. In this connection, along with the development of

* Corresponding author: geo-lipina@rambler.ru 
the concept of state sustainable development, strategic development becomes increasingly important in relation to specific producing regions. They are based are based on knowledge of the current state of the environment in the areas of former, existing and projected mining enterprises, as well as on predictive estimates of the trend of this state change for the future. The patterns of formation and development of regional natural-technical systems can not be studied without cartographic materials.

\section{Depth of the problem}

Many scientists have noted the interaction of the natural environment and technical objects in the areas of industrial development in their works, such as Buzmakov SA, Van AV, Zinyukov Yu.M., Revzon A.L. [3-5] The scientific works of a number of authors aimed at increasing the geoecological safety of the PTS have been considered: in the works on methodological provision, V.I. Osipova, I.I. Mazur, N.F. Reimers, N.N. Moiseeva, V.I. Danilov-Danilyan, and others; on the assessment of geoecological safety in the interaction of technical systems and the natural environment - V.A. Gracheva, V.M. Kotlyakova, A.L. Revzon, Boris G. Saxin, A.M. Ivleva, TN. Alexandrova, L.T. Krupskaya and others; on environmental design and expertise - K.N. Dyakonova, A.V. Donchevoy and others. It is established that the natural and technical systems that are formed during the mining of mineral deposits include natural, ore-dressing combines that function as a whole, have not been studied well enough. Therefore, the solution of the main issues related to the problems of research of NTS with a developed mining industry based on the example of Primorsky Krai, as well as the creation of a basis for constructing survey forecast ecological maps, is an urgent task.

\section{Methods of work and results}

A set of scientific methods was used, including: analysis and generalization of the literature data; mathematical and statistical processing of the obtained data, cartographic analysis.

In environmental terms, the main sources of environmental impact are mining and processing plants, the negative impact of which has recently acquired a large scale, including in the Primorsky Territory of the Far East.

Natural and man-made systems are increasingly replacing the natural environment. Analyzing the environmental component of the NTS, which can be said that any production process is necessarily interconnected with the natural environment, the components of which usually act as labor items. At the same time, as a result of the work, substances, energy and information that are as part of natural components that did not previously participate in the technological cycle are formed[6,7].

Considering the development of Primorsky Krai (the Southern margin of the Far Eastern economic region) as a region with a highly developed mining industry, it can be noted that deposits of coals, lead, zinc, tin, gold, silver, tungsten, fluorspar and boron ore are widely represented here.The mining industry supplies raw materials to non-ferrous metallurgy, as it develops polymetallic ores and fluorspar in the territory of the region. There is also a number of developed coal deposits.In the province, tungsten and lead concentrates, tin, boron products are produced. [8] In the volume of industrial production in the Primorsky Territory, the share of non-ferrous metallurgy is $3.2 \%$, but its significance is determined not so much by the total volume of production as by the city-forming nature of its leading enterprises and by the presence in edge of a unique raw materials base for fluorspar, tungsten, polymetals. The leading enterprises of the non-ferrous metallurgy industry in the Primorsky Territory include OJSC MMC Dalpolimetall, OJSC Primorskiy 
GOK, OJSC Yaroslavsky GOK, OJSC Lermontovskaya GRK. Primorye produces $80 \%$ of the Russian volumes of tungsten concentrate and fluorspar, 30\% of lead, $15 \%$ of zinc. As far as mining chemistry is concerned, Bor's open-cast mines contain raw materials of boron-containing raw materials, unique for the country.

The extraction of gold in the province was conducted from the middle of the nineteenth century on small but numerous placers, which were quickly worked out. At present, the Primorsky Region is significantly inferior to other subjects of the Far Eastern Federal District with a developed gold mining specialization in the mineral and raw materials sector of the economy. Due to the active geological study of the gold content of the region in recent years, a number of previously known and newly identified ore-placer sites have been reassessed and new deposits have been discovered. Containing gold were polymetallic, tin, tungsten ores, more recently known deposits of the region:: Primorskoye $11.49 \mathrm{~g} / \mathrm{t}$ gold, Vostok-2 - $1.4 \mathrm{~g} / \mathrm{t}$, Silinskoe $-0.98 \mathrm{~g} / \mathrm{t}$, Taiga - $0.63 \mathrm{~g} / \mathrm{t}$, etc. [9]. According to the official data of the gold deposit on the territory of the region, registered in the State Reserves Committee, according to VSEGEI, 2007 with additions from various sources are: Glukhoye and Morskoye (reconnaissance), Progress and Silan (undistributed), Vostok-2 and Taiga (being developed).

The extraction of ore gold (tailing production) in recent years is mainly carried out at the Vostok-2 field, about 200-250 kg per year. The tin deposits of the Primorsky Territory are of three types: tin-quartz, tin-silicate and tin-sulfide. The Tigrinoye deposit, the largest in the region, is of the first type,the ore of which is of poor quality. Among the small deposits of tin-silicate and tin-sulfide types, there are objects with rich ores. The extraction of tin, at present, is conducted in small volumes.

Nikolaevskoe deposit belongs to the skarn-polymetallic type (Dalnegorsky ore district), which is leading in the extraction of non-ferrous metals in the Dalnegorsky ore district of Primorye. In addition to the basic elements (lead and zinc), industrially significant concentrations in the ores are: $\mathrm{Ag}, \mathrm{Bi}, \mathrm{Cd}, \mathrm{In}, \mathrm{Se}, \mathrm{Te}, \mathrm{Cu}$, which can be extracted and partially recovered during ore processing.

The main mining enterprises of the Primorsky Territory are shown in Fig. 1.

Anthropogenic activity inevitably leads to a disturbance of the ecological balance in nature.

The concept of ecological balance has a profound meaning, since it relies on an extensive system of scientific knowledge and ideas about the status and properties of biogeocoenoses, as a set of abiotic environmental factors within a single territory, interconnected by the circulation of substances and the flow of energy (natural ecosystem). Natural balance due to anthropogenic impact tends to shift. In the development of indigenous ore deposits, four main types of solid waste are formed, which affect natural systems and form the main processes of mining technogenesis. 


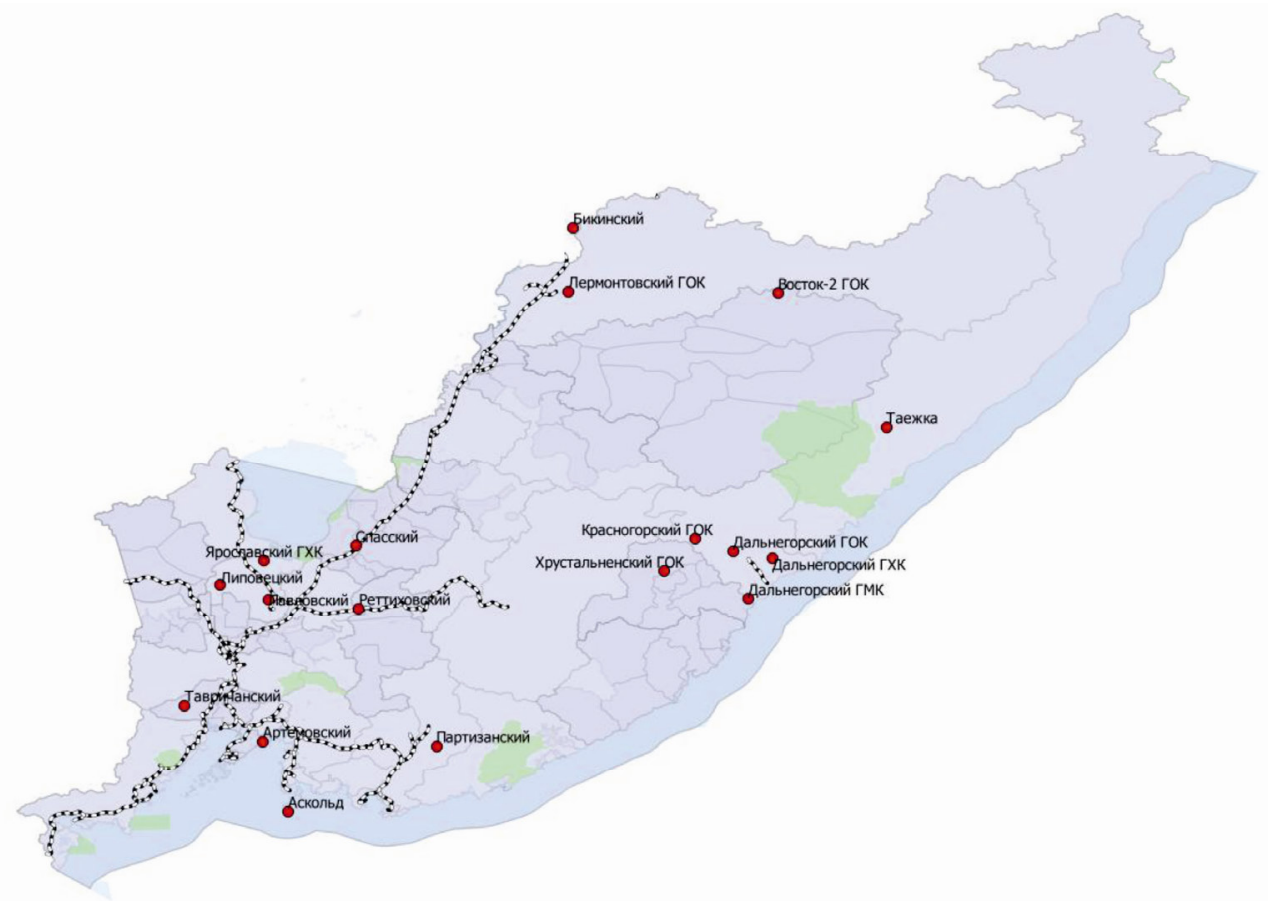

Fig.1. Mining industrial complexes of Primorsky Krai

These include: dumps of overburden, ore-bearing rocks and sub-standard ores; solid phase of processing waste, effluents of liquid saturated solutions; gas emissions. One of the features of the mining industry, as a result of which, the greatest amount of waste is generated, whose volumes are $60-95 \%$, and for rare metals and more from the volume of processed rock mass. Waste, in addition to occupying large areas, often very valuable land (forest fund) lead to significant changes in the environment. Not only the original landscapes change, but the natural geochemical equilibrium also changes. There is an intensive pollution of soils and reservoirs in the adjacent areas, a decrease in their biological productivity. At the same time, the negative processes associated with the violation of the main components of the environment are a long-term impact after the cessation of the production activities of enterprises.

An insignificant amount of solid wastes are losses of ores on transport communications within the mining areas (from mines to concentrating mills etc.), as well as dust emissions from crushing and filtering and drying shops of concentrating mills. In general, the technogenic impact of mining processes on ecosystem components is quite diverse, especially in the full technological cycle of production, so it becomes need to consider the various stages of production (Table 1).

If the stages of development and the stages of individual mining work are to be considered, it is necessary to assess the impact of mining on the environment in the aspect of two issues having important methodological significance: what and in what volumes is introduced and how can the ecosystem respond to this or that intervention.

At the first and second stages of mining, it must be taken into account that ore deposits and their primary haloes are natural foci of chemical contamination of the components of the natural environment by heavy metals, and the products of technogenesis that arise during their industrial development form ecologically dangerous halos and scattering streams that significantly affect the state and metamorphization ecosystems. 
Table 1. Stages of development of mining operations and sources of impact on ecosystems

\begin{tabular}{|l|l|l|}
\hline Stages & $\begin{array}{l}\text { Stage of development } \\
\text { and stages of mining }\end{array}$ & Sources of impact on ecosystems \\
\hline I & $\begin{array}{l}\text { Exploration and } \\
\text { development of the } \\
\text { deposit }\end{array}$ & $\begin{array}{l}\text { Mechanical dumps of enclosing rocks and sub- } \\
\text { standard ores; mine drainage of mineralized waters of } \\
\text { the oxidation zone }\end{array}$ \\
\hline $\begin{array}{l}\text { The stage of extraction } \\
\text { and transfer to the surface } \\
\text { of the ore mass }\end{array}$ & $\begin{array}{l}\text { Mechanical dumps of enclosing rocks and sub- } \\
\text { standard ores; mine drainage of mineralized waters of } \\
\text { the oxidation zone; gas-dust extraction during drilling } \\
\text { and blasting operations; dusting during transportation, } \\
\text { deflation of dumps and ore stores, etc. }\end{array}$ \\
\hline III & The stage of ore dressing & $\begin{array}{l}\text { Construction and formation of tailing ponds and sludge } \\
\text { pits; emergency emissions from slurry pipelines and } \\
\text { tailing dumps, ventilation systems of the concentrating } \\
\text { mills and transportation of ore; outputs of } \\
\text { technological preparations and suspensions into open } \\
\text { reservoirs }\end{array}$ \\
\hline IV & $\begin{array}{l}\text { Metallurgical } \\
\text { redistribution of ore } \\
\text { concentrates }\end{array}$ & $\begin{array}{l}\text { Technological liquid and gas emissions; } \\
\text { metallurgical ash dumps and slag-dump; } \\
\text { emissions of auxiliary industries }\end{array}$ \\
\hline
\end{tabular}

When considering the III and IV stages of work, depending on what concentrations and types of toxicants are inherent in this geoecological type of ores, appropriate technological regulations for ore processing should be developed and implemented. In essence, the indicator of toxicity of an ore deposit is, first of all, the level of sulphide content (concentrations) of toxic elements, as well as the most important chemical mineralizers that accompany them, which form migration-capable forms of toxicants in the hypergenesis zone. The latter are formed, first of all, due to the minerals easily soluble in the oxidation zone: sulfates, carbonates, arsenates, phosphates, etc. To determine the value of the toxicity indicator of the deposit, it is proposed to use the total indices of the content of toxicants $(\Sigma \mathrm{Kc})$ in the ores of the deposit.

Based on the research conducted at the Mining Institute of the Far East RAS, it has been established that sulfide-sulfate technogenesis processes are actively manifested in production wastes even with insignificant (from 1 to 5\%) sulfur contents, processes occurring in mineral wastes (oxidation of sulfides to sulfates) have a negative impact on the environment. Therefore, technological and geological factors in the development of specific mining objects, the results of which should be taken into account in ecological mapping, are of great importance for the environmental status of mapping of natural and man-made systems. But, it is also necessary to take into account the most "strong" natural component, the lithogenic basis, that determines the geochemical background (the environment in which chemical reactions take place) in ecological mapping of natural and man-made systems. The most illustrative example of the carbonate base: in waters with carbonate hardness, positive ions of heavy metals bind to the carbonate ion and precipitate, the acids are quickly neutralized. The violation of the lithogenic base often leads to a complete transformation of the ecosystem (technogenic complexes). The influence of the lithogenic base is traced at all stages of field exploitation.

Based on the geological map of Primorsky Region [10], a map of the lithogenic substrate was created using geographic information systems (GIS) for Primorsky Region. At the first stage, a legend was developed (Figure 2), which reflects the main classes of the lithogenic substrate, then drawing up the map layout. Using the QGIS program, which is distributed under the GNU GPL license [11], the compiled map is digitized in layers, according to the designations. As the geographical basis of the map was adopted: Open 
Street Map (OSM), Russified [12], in the geographical projection lat / long, on the ellipsoid WGS84, freely distributed via the Internet.

The creation of maps of the lithogenic substrate can be considered as the initial stage of landscape-geochemical mapping of the territory.

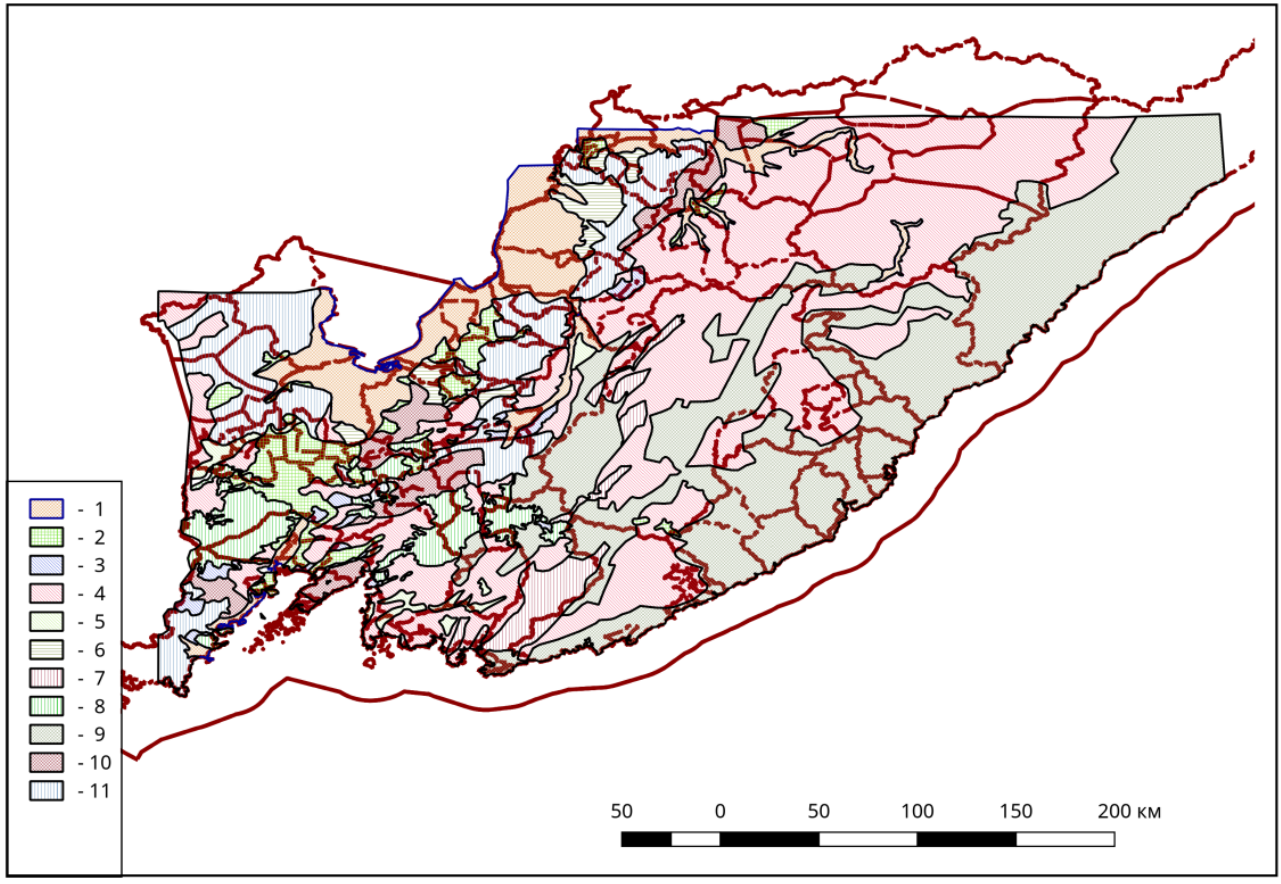

1 - Alluvial quaternary formations (Q_Al); 2 - Alluvial-lacustrine, lacustrine formations of N-Q age (N-Q_Al-lake); 3 - Cenozoic carboniferous deposits (KZ_Coal); 4 - Terrigenous Pz3 - Mz sediments (PZ3-MZ_terr); 5 - Terrigenous coal-bearing Pz3 - Mz sediments (PZ3-MZ_coal); 6 Carbonate and carbonate-containing rocks (limestones, marbles, dolomites) (Carbonate); 7 - Basic and ultrabasic magmatic complexes, including plateausal basalts (Base_Magm); 8 - Extrusive diabase-basalt complexes and covers of Neogene plateaus of basalts ( $\mathrm{N}_{-} \mathrm{db}-$ basalt $) ; 9$ - Magmatic (volcanic, intrusive-volcanic) complexes of medium and acid composition (Mz magm); 10 Volcanogenic and intrusive-volcanogenic complexes of the Late Mesozoic (Mz-late_Volcan); 11 Precambrian-Paleozoic granitoids of the Khanka massif, gneisses, crystalline schists (Pre_Cm).

Fig.2. Map of the lithogenic substrate of Primorsky Region

The obtained results can serve as a basis both for preparing the initial information for the development of ecological maps of a new generation, and for creating a database for various classes and subclasses of elementary landscapes.

\section{References}

1. Trubetskoi K.N. State and perspective directions of development of mining in Russia // Geoecology. Engineering geology. Hydrogeology. Geocryology. 6. P. 3-7. (2017)

2. Vernadsky VI Biosphere. M. Thought, (1967).

3. Buzmakov, S.A. Ecology and nature management in conditions of anthropogenic transformation of the natural environment / Geography and region. Materials of the International. sci. Pract. Conf .: in 6 volumes. - PGNIU, P. 22-27. (2015).

4. Wang, A.V. Methodological problems of research of natural ecological and naturaltechnical systems / INTEREXPO GEO-SIBERIA. 3 (2). P. 33-38. (2012). 
5. International mining strategy of mining investment-geological science-information integration. Ding Qun-an, Wang Lin, Huang Xing-wen, Jiang Ya. $/$ Ziyuan yu chanue = Resour / and Ind. 4, p 1-12. (2016).

6. Saksin, B.G. Forecasting the regional geochemical impact on the environment of mining enterprises of non-ferrous metallurgy in the East of Russia. Khabarovsk: IGD FEB RAS. 190 p. (2012).

7. Sekisov GV, Grekhnev NI, Romanov VG, Zykov NV Ecological efficiency of technologies for the development of deposits of solid minerals and methodological principles for its evaluation // Mining Journal. 3. P. 112-119. (2007).

8. http://www.wiki-prom.ru/region/primorskiy_kray.html.

9. Arkhipov G.I. Khabarovsk: Institute of Mining, Far East Division, Russian Academy of Sciences, 820 p. (2017).

10. "Geological map of the Primorsky Krai", M 1: 500000 and 1: 1000 000. They composed: V.A. Baksanov; L.F. Navarenko, Yu.N. Oleynik (1988).

11. http://www.gnu.org/licenses/gpl.html

12. http://gis-lab.info/projects/osm-export.html 